\title{
Staged-Fault Testing of Distance Protection Relay Settings
}

\author{
J. Havelka ${ }^{1}$, R. Malarić ${ }^{1}$, K. Frlan ${ }^{2}$ \\ ${ }^{1}$ Faculty of Electrical Engineering and Computing, University in Zagreb, Unska 3, 10000 Zagreb, Croatia, \\ juraj.havelka@fer.hr \\ ${ }^{2}$ HEP- Transmission System Operator, M. Tita 166, Opatija, Croatia, kristijan.frlan@hep.hr
}

\begin{abstract}
In order to analyze the operation of the protection system during induced fault testing in the Croatian power system, a simulation using the CAPE software has been performed. The CAPE software (Computer-Aided Protection Engineering) is expert software intended primarily for relay protection engineers, which calculates current and voltage values during faults in the power system, so that relay protection devices can be properly set up. Once the accuracy of the simulation model had been confirmed, a series of simulations were performed in order to obtain the optimal fault location to test the protection system. The simulation results were used to specify the test sequence definitions for the end-to-end relay testing using advanced testing equipment with GPS synchronization for secondary injection in protection schemes based on communication. The objective of the end-to-end testing was to perform field validation of the protection settings, including verification of the circuit breaker operation, telecommunication channel time and the effectiveness of the relay algorithms. Once the end-to-end secondary injection testing had been completed, the induced fault testing was performed with three-end lines loaded and in service. This paper describes and analyses the test procedure, consisting of CAPE simulations, end-to-end test with advanced secondary equipment and staged-fault test of a three-end power line in the Croatian transmission system.
\end{abstract}

Keywords: Distance protection, three-end line, Croatian power system, protection, fault, simulation, teleprotection scheme, communication

\section{INTRODUCTION}

$\mathrm{T}$ HE OBJECTIVE of staged-fault testing in the Croatian power system was to evaluate the performance of the distance teleprotection scheme [1], to collect fault data [2] and verify coverage [3] on a three-end line due to in feed/out feed effects. The $110 \mathrm{kV}$ three-end line in the western part of the Croatian power system known as the Istrian peninsula has been recently added to improve fault clearing times and transient energy flows associated with a specific power system configuration. Since a three line structure is otherwise not present in the Croatian power system, this three-end line has provided good base for analysis and data collection. The Istrian peninsula has two thermal power plants, one of 156 MVA at the voltage level of $110 \mathrm{kV}$ and the second of $263 \mathrm{MVA}$ at the voltage level of $220 \mathrm{kV}$, both situated at the same site. Each fault, regardless of its type and location is fed directly and indirectly from those power plants, as the only strong sources in the region. The unevenness of the power flow and fault current contribution can lead to wrong operation of distance protection relays. In order to improve safety of the power system, two new $110 \mathrm{kV}$ lines were constructed. One of them is a three-end line, for which a teleprotection distance scheme was implemented. Distance zone settings were calculated using the CAPE software [4], in which simulations for different faults and network configurations were performed. Three-end lines are not common in the Croatian power system, and the analyzed line is the first of this kind in the western part of the Croatian power system. This was one of the reasons why it was decided to test the protection system using staged-fault testing. Due to the fact that this kind of testing requires considerable preparations, the work was divided into three main steps:
1. voltage values during each fault for end-to-end testing

2. GPS synchronized [5] end-to-end testing in order to analyze the relay settings and telecommunication system

3. Staged-fault testing

\section{CROATIAN POWER SYSTEM}

The Croatian power system is interconnected with the systems of the neighboring countries and together with them it is connected into the European ENTSO-E (European Network of Transmission System Operators for Electricity) synchronous network. As for its size, the Croatian power system (PS) is one of the smallest PSs in Europe, but due to its geographical position and location it is important for northern and western ENTSO-E interconnection. The Croatian PS transmission is governed independently by HEP Transmission System Operator, which is divided into four transmission areas. Analyzed part of the Croatian power system is shown in Fig.1.

The western area which is of concern in this paper consists of a developed $110 \mathrm{kV}$ and $220 \mathrm{kV}$ network and two thermal power plants: Plomin 1 (156 MVA) at the voltage level of $110 \mathrm{kV}$ and Plomin 2 (263 MVA) at the voltage level of 220 $\mathrm{kV}$. Since these thermal power plants are on the same site, the $220 \mathrm{kV}$ and $110 \mathrm{kV}$ voltage levels are interconnected through 3 autotransformers rated at 150 MVA each. The thermal power plants are connected to 2 major substations: Melina 400/220/110 kV and Pehlin 220/110 kV with two lines at the voltage level of $220 \mathrm{kV}$ and one with $110 \mathrm{kV}$ to the remaining part of the Croatian power system. In the north of the Istrian peninsula there is a $110 \mathrm{kV}$ interconnection with the Slovenian TSO (Fig.2). 
The main distance protection on all lines is of electromechanical, static and numerical type. Particular flows of energy during faults in the western power system are caused by its configuration. Each fault, regardless of its type and location, is fed directly and indirectly from the thermal power plant Plomin 220/110 kV as the only strong source.

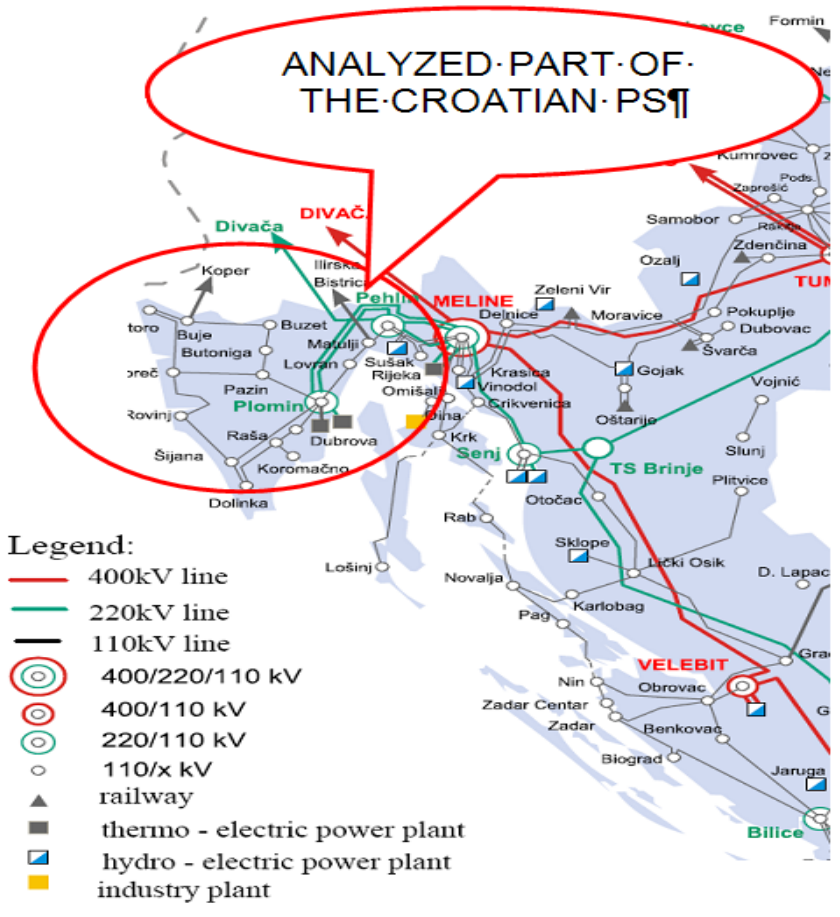

Fig.1. Croatian Power System

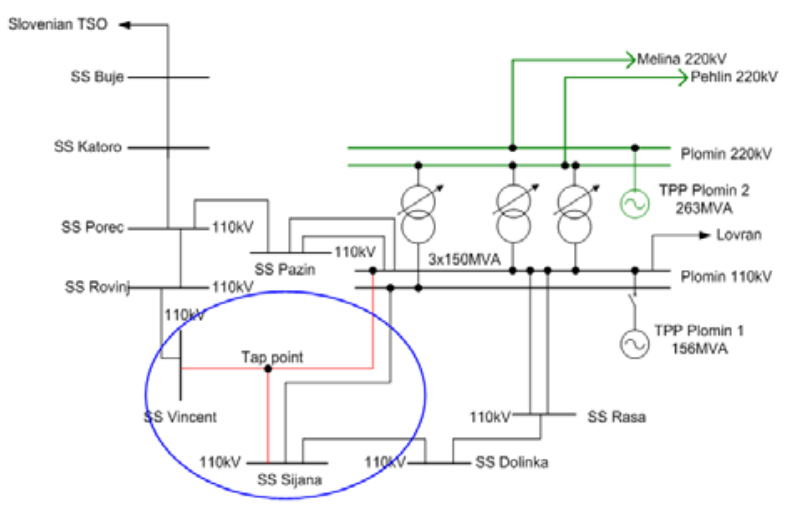

Fig.2. Western part of the Croatian PS

\section{Three-end line TPP Plomin - SS Sijana - SS Vincent}

The three-end line between substations Plomin - Sijana Vincent was constructed as a $220 \mathrm{kV}$ overhead line, but it is temporarily in service at the $110 \mathrm{kV}$ voltage level. It also contributes to balancing the distribution of the fault current which improves the operation of the relay protection system. The length of each branch of the line is given in Table 1 . The main issue when setting the relay protection system is difference in line length of each branch and uneven fault current distribution.
Table 1. Three end line data

\begin{tabular}{cc||cc} 
BRANCH: & $\begin{array}{c}\text { LENGT } \\
\mathrm{H}[\mathrm{KM}]\end{array}$ & $\mathrm{ZD}[\Omega]$ & $\mathrm{Z} 0[\Omega]$ \\
\hline \hline $\begin{array}{c}\text { Plomin - Junction } \\
\text { point }\end{array}$ & 33.1 & $1.832+\mathrm{j} 13.83$ & $6.62+\mathrm{j} 39.85$ \\
$\begin{array}{c}\text { Vincent - Junction } \\
\text { point } \\
\text { Sijana - Junction } \\
\text { point }\end{array}$ & 24.34 & $2.92+\mathrm{j} 10.17$ & $12.04+\mathrm{j} 26.1$ \\
\hline & 10.11 & $1.214+\mathrm{j} 4.22$ & $3.541+\mathrm{j} 10.8$ \\
\hline
\end{tabular}

\section{RELAY PROTECTION SYSTEM CONFIGURATION}

\section{A. Distance protection settings}

Although differential protection scheme might be a better option for the protection of the three-end line, protection devices used at the line ends are distance numerical relays which were already installed at each substation. Thus, the allocation of these distance protection devices with teleprotection scheme was chosen as the main protection for the multi-terminal line Plomin-Sijana-Vincent. The problem encountered during the setting and commissioning of the devices was the fact that the relays are produced by different manufacturers with different firmware.

The unevenness of the current distribution in the network was the main problem during the planning stage of the distance teleprotection scheme. The distance protection algorithm determines the distance to the fault location based on measured analog values (current and voltage). Due to uneven fault current distribution the impedance "seen“ by the distance relay is not always the actual line impedance from a relay terminal to the point of fault. This is because the relay measures impedances based on the voltage drop between its location and the fault and the line current at its location. Thus, the impedance ,seen“ by the relay depends upon the current contributions from the other terminals, which can result in incorrect operation [6].

Permissive underreaching transfer trip scheme (PUTT) was chosen as the teleprotection scheme [7]. This type of teleprotection scheme requires reliable telecommunication infrastructure for the operation criteria transmission from one line end to the other, or in this instance, two remaining ends. In the case of a fault inside the $\mathrm{Z} 1$ zone, the transfer trip signal is sent to the opposite line end. The signal received there initiates the trip, provided that the distance protection function has picked up. Regardless of the relay scheme in which they are employed, Zone 1 distance functions must be set in such a way as not to overreach the opposite line end. Typical settings would be 85 to 90 percent of the positive sequence line impedance. The picked up zone (the overreaching zone) is most commonly set to $120-130$ $\%$ of the protected line (Zone 2, Z2) [8].

By simulating faults using the CAPE software in different locations of the protected line the conclusion was reached that the relay in the substation TPP Plomin does not misoperate during fault location calculation, while the relays in substation SS Sijana, and particularly in substation Vincent, do. This can be caused either by fault resistance or in/out-feed event. Therefore, it was not possible to adjust the relay at 85-90 percent of the protected line. The relays were set in such a way that Zone $1(\mathrm{Z1})$ of each relay reaches beyond the tap point, while the overreaching zone, which at 
the same time accelerates relay operation with the reception of transfer trip signal, was extended to Zone 4 (Z4). Fig.3, 4 and 5 show the relay settings calculated using CAPE software, for the relays at TPP Plomin, SS Sijana and SS Vincent, respectively.

Tripping logic was set in the following way:

- single-phase trip for single-phase faults and three-phase trip for multi-phase faults

- auto-reclosure (AR) of a single-phase trip with dead time of 1.2 seconds, and of a three-phase trip with dead time of 0.3 seconds AR is permitted only after the relay operation in Zone 1 (Z1), or after the reception of transfer trip signal with pick up in overreaching zone.

- When PP Plomin is out of operation for maintenance, protection settings are the same because of the connection transformer in PP Plomin $(220 \mathrm{kV} / 110 \mathrm{kV})$.

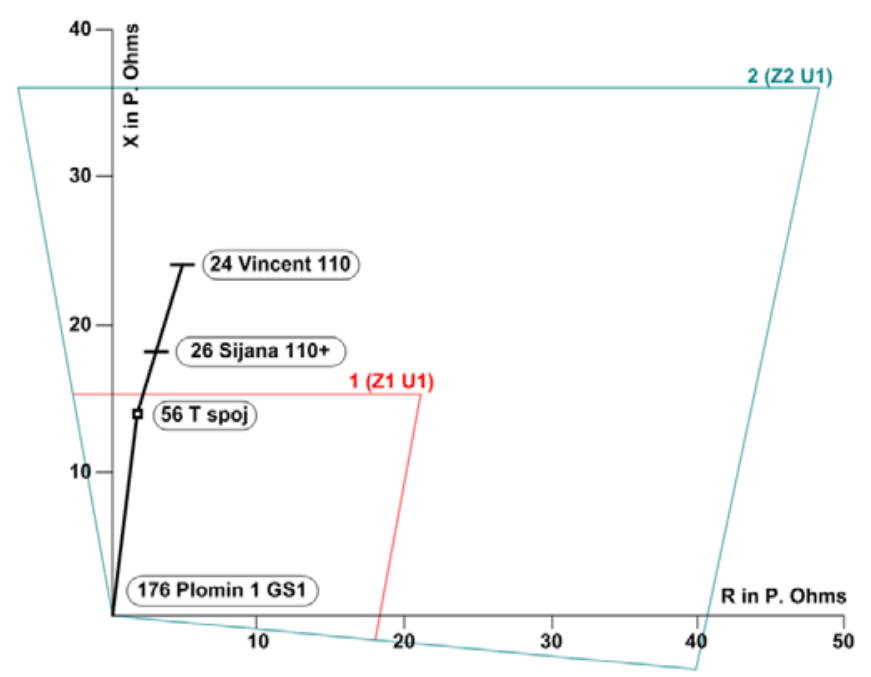

Fig.3. Relay setting for TPP Plomin

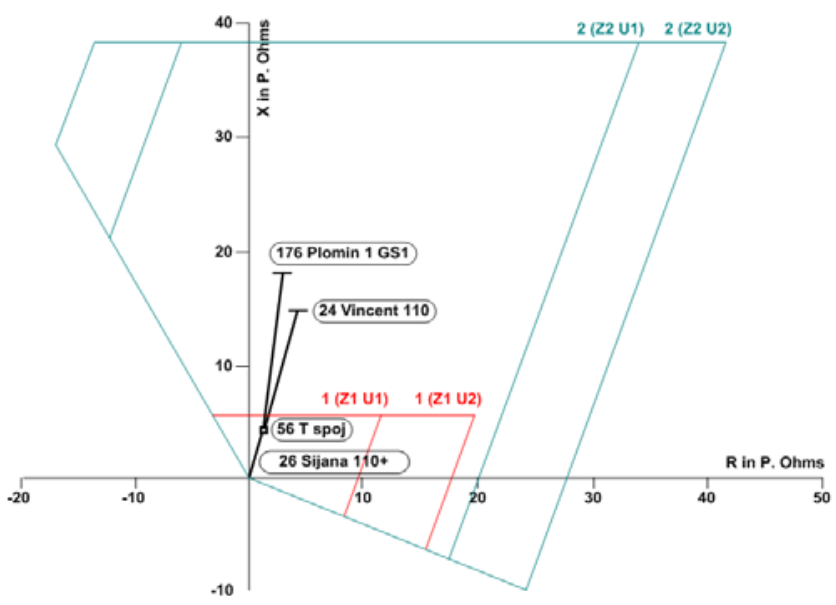

Fig.4. Relay setting for SS Sijana

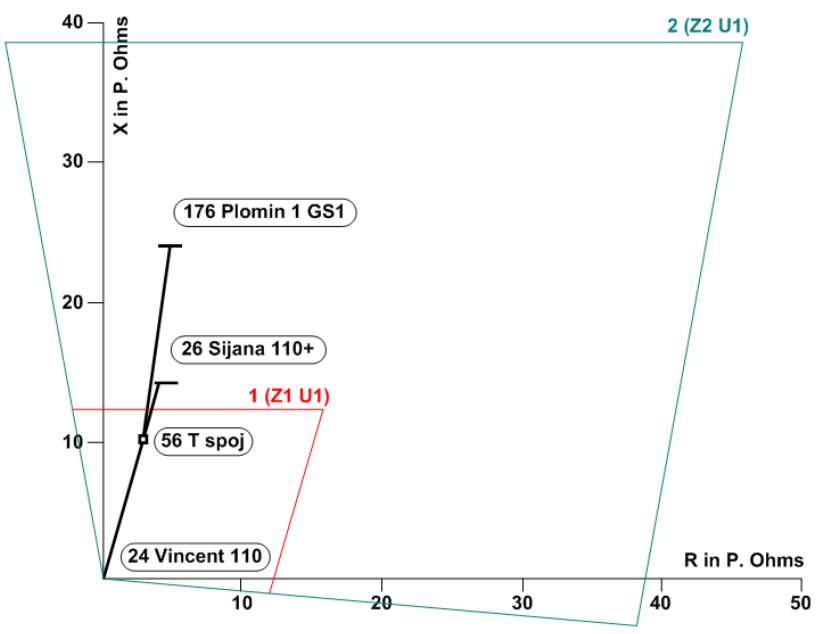

Fig.5. Relay setting for SS Vincent

\section{B. Telecommunication System Configuration}

Telecommunication among relays is achieved with telecommunication devices meant for transmission of teleprotection controls and the digital network. The relay operating in Zone 1 (Z1) issues a trip signal for its breaker and also a transfer trip signal which is sent to other two relays at the same time. The first telecommunication device receives the permissive signal for faster operation as a voltage impulse, transforms it into analog frequency signal (frequency of $887 \mathrm{~Hz}$ ) and sends it to the second telecommunication device. The latter receives this analog frequency signal and transforms it into a digital signal which is sent via digital network to other relays, i.e. telecommunication devices.

To increase the reliability of the telecommunication system, the system configuration is deployed with redundant connections. During relay operation in Z1 the transfer trip signal is sent to two remaining relays using two routes. The first route is a direct connection between relays, and in the second route the signal receiving telecommunication device redirects it to the relay which is not the source of the signal.

The signal transmission is continuously under supervision. The devices exchange analog signals of $2720 \mathrm{~Hz}$ between themselves which are transformed into a digital signal and transferred to the chosen destination. If exchange of the signal for supervision is interrupted, it means that the communication line is interrupted and the entire protection system cannot work properly. Fig. 6 is a block diagram representation of how the telecommunication system operates in case the relay at TPP Plomin issues a permissive transfer trip signal. If the telecommunication system is out of operation, then each relay works independent of each other. As relay selectivity is not met in that case, the telecommunication system should be repaired as soon as possible. 


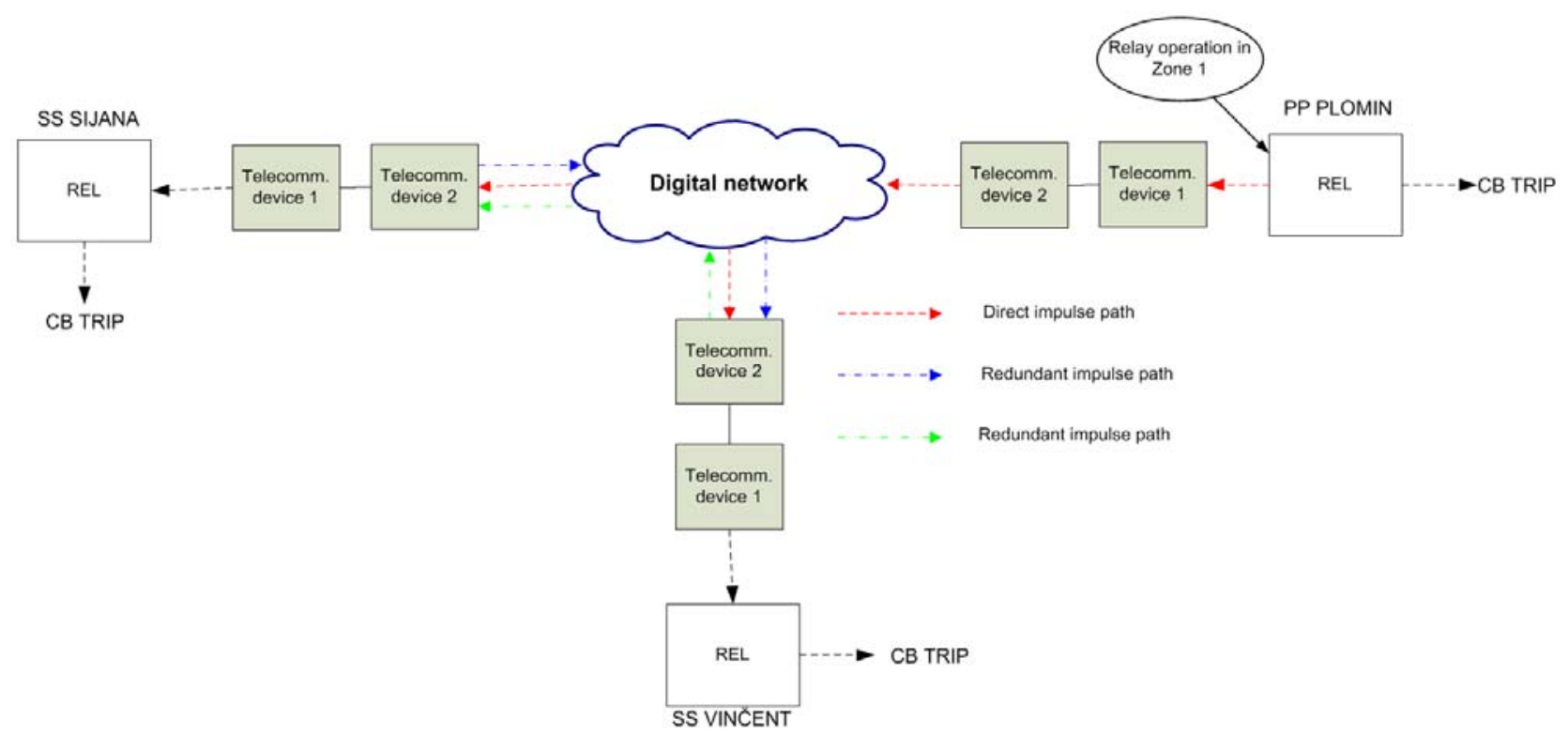

Fig.6. Telecommunication system operation

\section{SiMULATIONS IN CAPE SOFTWARE}

In order to obtain general guidelines regarding the system operation during fault testing in the network, the simulation by the CAPE software was performed $[9,10,4,12]$. The CAPE (Computer-Aided Protection Engineering) software has been already in use for several years in the HEP TSO. It is commercially available expert software intended primarily for relay protection engineers. It calculates current and voltage values during faults in the power system, so that appropriate settings of relay protection devices can be chosen. It should be mentioned that all three power line ends were sources of the short circuit current. The program modules contained in this software enable the analysis of power system abnormality, as well as future network planning, with the additional possibility of adding all the elements of the power system important for the functioning of the relay protection system: lines, transformers, generators, measuring transformers, circuit breakers and relay protection devices.

It was decided that the tower number 49 on the line TPP
Plomin $1-\mathrm{T}$ junction would be the point of fault testing. This tower is located on $49.46 \%$ of the line length, that is, $16.234 \mathrm{~km}$ away from TPP Plomin. Using the Short Circuit module [9] and Coordination Graphic module [4] the tower number 49 was chosen as the simulations showed that the fault on this point is inside the Z1 of the relay at TPP Plomin, and inside Z2 for the relays at SS Sijana and SS Vincent. According to the simulations the relays at Sijana and Vincent make the biggest miscalculations of the fault location. In this way the relays as well as the telecommunication systems for the transmission of criteria for distance protection operation (transfer trip signal) can be tested for the worst case scenario. That is the reason why this location was selected.

Due to tripping logic setting (1/3p trip/AR), two different fault types were simulated, single line-to-ground and a lineto-line fault. The results from the CAPE simulations are shown in Table 2.

Table 3 shows voltages at buses for the fault at tower 49 for different fault types.

Table 2. Current contributions for the fault at tower 49 for different fault types

\begin{tabular}{|c|c|c|c|c|c|}
\hline \multirow{2}{*}{ LoCATION } & \multirow{2}{*}{ FAULT TYPE } & \multicolumn{4}{|c|}{$\mathrm{I}$ [A] (SIMULATED RELAY CURRENT) } \\
\cline { 3 - 6 } & & $\mathrm{I}_{\mathrm{L} 1}$ & $\mathrm{I}_{\mathrm{L} 2}$ & $\mathrm{I}_{\mathrm{L} 3}$ & $3 \mathrm{I}_{0}$ \\
\hline \multirow{3}{*}{ PLOMIN } & $\mathrm{L} 1-\mathrm{E}$ & $3906.6 \angle 82.441^{\circ}$ & $120 \angle 90.549^{\circ}$ & $120 \angle 90.413^{\circ}$ & $3667.8 \angle-81.978^{\circ}$ \\
\cline { 2 - 6 } & $\mathrm{L} 2-\mathrm{L} 3$ & $0.6 \angle-61.791^{\circ}$ & $3963.0 \angle-173.395^{\circ}$ & $3963.0 \angle 6.609^{\circ}$ & $/$ \\
\hline \multirow{2}{*}{ ŠIJANA } & $\mathrm{L} 1-\mathrm{E}$ & $1311 \angle-77.872^{\circ}$ & $130.2 \angle-86.683^{\circ}$ & $130.2 \angle-86.875^{\circ}$ & $1568.4 \angle-79.342^{\circ}$ \\
\cline { 2 - 6 } & $\mathrm{L} 2-\mathrm{L} 3$ & $0.6 \angle 89.807^{\circ}$ & $1164.6 \angle-167.628^{\circ}$ & $1164.6 \angle 12.351^{\circ}$ & $/$ \\
\hline \multirow{2}{*}{ VINČENT } & L1-E & $572.4 \angle-77.529^{\circ}$ & $11.4 \angle 123.354^{\circ}$ & $11.4 \angle 123.143^{\circ}$ & $551.4 \angle-78.37^{\circ}$ \\
\cline { 2 - 6 } & $\mathrm{L} 2-\mathrm{L} 3$ & $0.000 \angle-136.181^{\circ}$ & $574.2 \angle-167.876^{\circ}$ & $574.2 \angle 12.136^{\circ}$ & $/$ \\
\hline
\end{tabular}


MEASUREMENT SCIENCE REVIEW, Volume 12, No. 3, 2012

Table 3. Voltage at buses for the fault at tower 49 for different fault types

\begin{tabular}{|c|c|c|c|c|}
\hline \multirow{2}{*}{ LoCATION } & \multirow{2}{*}{ FAULT TYPe } & \multicolumn{3}{|c|}{ PHASE VOLTAGE AT RELAY LOCATION [KV] } \\
\cline { 3 - 5 } & & $\mathrm{V}_{\mathrm{L} 1}$ & $\mathrm{~V}_{\mathrm{L} 2}$ & $\mathrm{~V}_{\mathrm{L} 3}$ \\
\hline \multirow{2}{*}{ PlOMIN } & L1-E & $32.1679 \angle 0.0^{\circ}$ & $62.0985 \angle-115.7^{\circ}$ & $61.8468 \angle 115.7^{\circ}$ \\
\cline { 2 - 5 } & L2-L3 & $65.5078 \angle-0.1^{\circ}$ & $44.6300 \angle-138.6^{\circ}$ & $43.6609 \angle 137.2^{\circ}$ \\
\hline \multirow{2}{*}{ ŠIJANA } & L1-E & $32.1679 \angle 0.0^{\circ}$ & $62.0985 \angle-115.7^{\circ}$ & $61.8468 \angle 115.7^{\circ}$ \\
\cline { 2 - 5 } & L2-L3 & $65.2110 \angle-0.1^{\circ}$ & $36.7378 \angle-150.2^{\circ}$ & $38.0226 \angle 151.2^{\circ}$ \\
\hline \multirow{2}{*}{ VINČENT } & L1-E & $31.8175 \angle 0.2^{\circ}$ & $62.3814 \angle-116.8^{\circ}$ & $62.5550 \angle 116.6^{\circ}$ \\
\cline { 2 - 5 } & L2-L3 & $65.1384 \angle-0.1^{\circ}$ & $37.2367 \angle-149.2^{\circ}$ & $38.3104 \angle 150.0^{\circ}$ \\
\hline
\end{tabular}

\section{END-TO-END TESTING}

The most common application of GPS-synchronized secondary injection end-to-end relay testing [13] is to verify line protection schemes of newly installed relays. The test is usually performed when a new substation is commissioned or during relay refurbishment projects. Its objective is to perform a complete check of the new system protection scheme, including verification of circuit breaker operation [14], telecommunication channels and the effectiveness of relay settings in service.

Timing accuracy is suitable for any kind of teleprotection scheme and no user correction for geographic location is needed.

The procedure and objectives of the end-to-end testing were specified as follows:

1) Protection schemes (schematics and relay settings)

2) Three teams (2 engineers on each side)

3) Synchronization test

4) Software and modules for end-to-end test

5) Test definition (location and types of faults)

6) Sequence definitions for all sides (pre-fault, fault and post-fault)

\section{A. Software and modules for end-to-end testing}

High precision and speed of measurement was important $[15,16]$. In regard to that the Omicron testing system was used in the end-to-end testing. Three Omicron testing devices with the GPS module synchronized via the GPS system, were used, each in a different substation.

\section{B. Test definition (location and types of faults)}

CAPE software was used to simulate faults in the location chosen for primary tests, i.e. $49^{\text {th }}$ tower from Plomin to the tap point, on $49.46 \%$ of the line length (that is, $16.234 \mathrm{~km}$ ) as described in section 4. Simulated faults were L1-E and L2-L3. In such a way the protection system could be checked for single line-to-ground faults, as well as phase-tophase faults.

\section{Sequence definition}

End-to-end testing was executed by using the so-called „state sequencer" (program module). Current and voltage values obtained through simulation using the CAPE software were used for the development of the sequences adjusted to each particular relay depending on the location in which it was installed. Each sequence consists of a prefault, fault and post-fault condition. Settings for pre-fault conditions were the same for all the relays. The current value for the pre-fault condition was $300 \mathrm{~A}$, which is the usual line loading. The fault conditions were extracted from the Short Circuit module of the CAPE software. Fig. 7 shows the waveform of the sequence definition for the single lineto-ground fault.

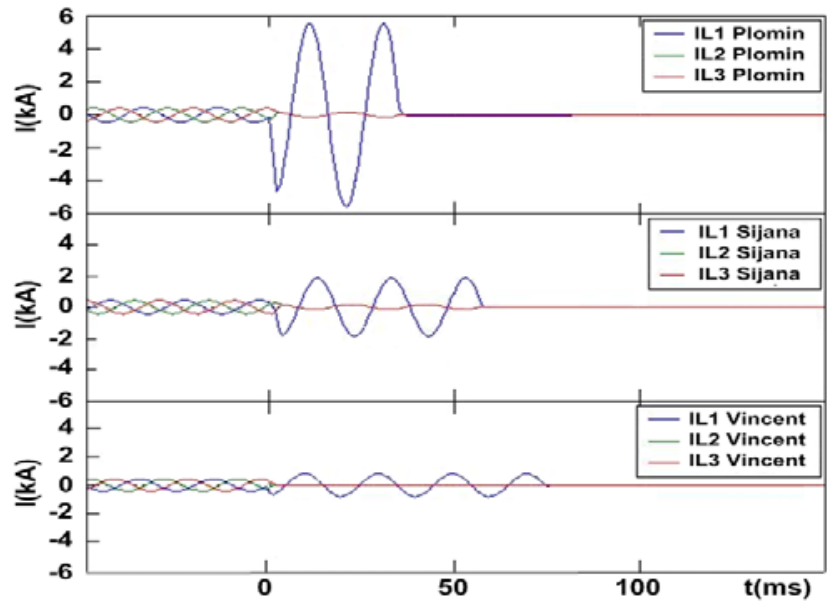

Fig.7. Phasor values sequence definition for endtoend testing for single linetoground fault

\section{Test implementation}

Three testing devices for secondary testing are interconnected by means of the GPS system. The prepared tests are initiated when GPS module gets a signal from the satellite and sends it to the testing device (Fig.8.). In such a way the three test sequence in three different locations starts at the same time.

The test procedure was defined as follows:

1) The test instruments are set up with the GPS synchronized time base.

2) The computer is set up running the test simulation software and connected to one of the instruments.

3) The engineers at each end communicate, select the appropriate test, enter the test time and then initiate the test. 
4) The test then runs automatically:

a. The test phasor values and test time are loaded via RS232 from the software running on the computer to the test instrument,

b. The time decoded from the GPS receiver and the test time from the program are continually compared,

c. When the receiver time equals the test time, the test data are replayed synchronously at each end of the line.

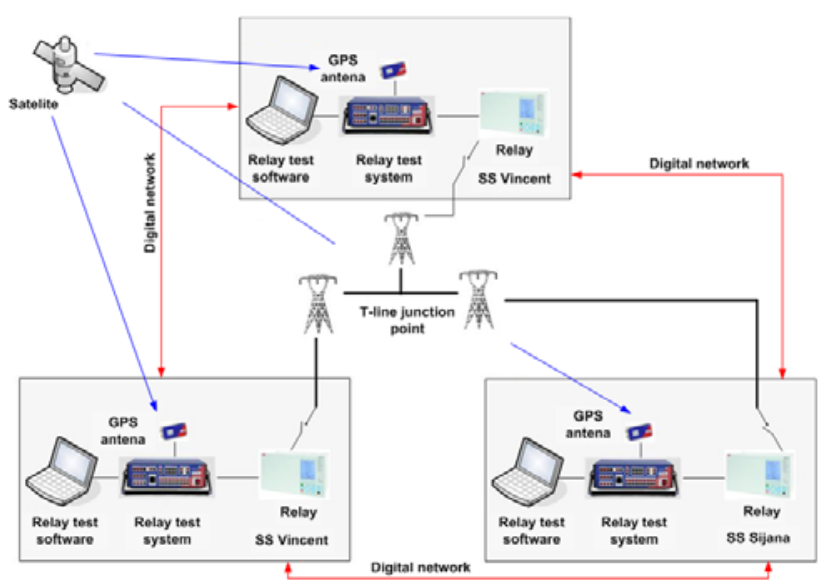

Fig.8. Endtoend relay testing system configuration

During examination the line was not in operation. The tests were performed for simulated fault L1-N without operation on the circuit breaker, L2-L3 without operation on the circuit breaker and L1-N with operation on the circuit breaker.

\section{E. Test results}

Analysis of relay operation was performed based on the records by numerical relays which were sampled at $0.5 \mathrm{~ms}$ intervals of $0.5 \mathrm{~ms}$ for the relays in SS/TPP Plomin and SS Vincent, and with $1 \mathrm{~ms}$ interval for the relay in SS Sijana. The relay in TPP Plomin detected a simulated fault in Z1, the relay in SS Sijana in Z2, as well as the SS Vincent. The relay in TPP Plomin operated without delay, and the relays in SS Sijana and SS Vincent operated after the reception of the transfer trip signal (otherwise they would have operated with delay time of $500 \mathrm{~ms}-$ Zone 2).After the analysis of numerical relay records from three different locations the following results were obtained:

- relay in TPP Plomin issues an order to trip the fault phase $24 \mathrm{~ms}$ after the occurrence of fault;

- based on the injected secondary values the relay detected fault on $47.5 \%$ of the line length, that is, $15.7 \mathrm{~km}$ for the simulated fault $\mathrm{L} 1-\mathrm{N}$, and on $49.6 \%$ of the line length, i.e. $16.4 \mathrm{~km}$ for the simulated fault L2-L3;

- relay in TPP Plomin issues an order to send the transfer trip signal $24 \mathrm{~ms}$ after the fault inception;

- relay in SS Sijana receives the transfer trip signal $48 \mathrm{~ms}$ after fault inception and issues an order for tripping. Signal transmission takes $24 \mathrm{~ms}$;

- relay in SS Vincent receives the transfer trip signal 55 $\mathrm{ms}$ after fault inception and issues an order for tripping. Signal transmission takes $31 \mathrm{~ms}$.
The obtained data show satisfactory operation of the protection system along with the communication part for the transmission of acceleration signal.

\section{THE ACTUAL TWO-PHASE FAULT ON THE THREE-END LINE}

A few days after the secondary end-to-end testing there was a two-phase fault (L1-L2) on the three-end line, due to bad weather conditions. In spite of the end-to-end testing a few days before, the teleprotection system failed in operation and the line was outaged.

The fault location was such that the relay in TPP Plomin detected the fault in Z1 and issued an order to switch the circuit breaker off and to transfer trip signal toward other relays $24 \mathrm{~ms}$ after the fault inception. In TPP Plomin there was a cycle of unsuccessful three-phase AR (dead time of $0.3 \mathrm{~s}$ ), as the relays at the other line ends did not operate simultaneously. The relays in other locations detected the fault in overreaching zone and could operate in an accelerated way only after receiving the transfer trip signal.

According to the fault record the relay in SS Sijana received the transfer trip signal $318 \mathrm{~ms}$ after the fault inception, as compared to the relay in SS Vincent, which received it $428 \mathrm{~ms}$ later. Signal transmission took $294 \mathrm{~ms}$ to SS Sijana, and $404 \mathrm{~ms}$ to SS Vincent. Fig.9 shows the relay recording of the fault for the relays at Plomin and Vincent. Both the analog and digital signals are shown in Fig.9.

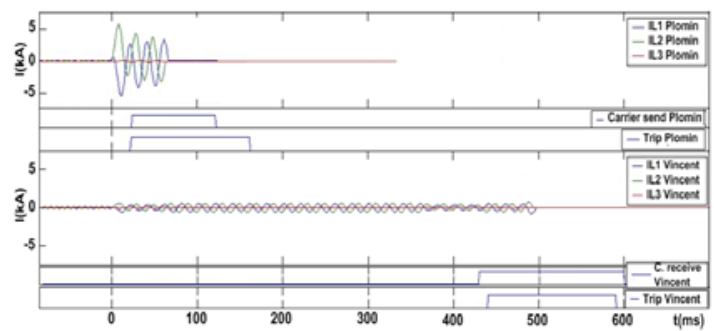

Fig.9. Relay recording of the two-phase fault on the three-end line

The setting logic in the relay in SS Sijana does not permit AR cycle if the reception of the signal for acceleration is late more than $200 \mathrm{~ms}$ after the occurrence of fault, so the relay issued an order for definitive three-pole tripping. The relay in SS Vincent managed to operate a cycle of three-phase AR, but only due to the fact that switches in TPP Plomin (unsuccessful AR) and SS Sijana (definitive tripping) were already switched off at the time. After the analysis of the observed occurrence the following conclusions were reached. The power of analog frequency signal, which the first telecommunication device sends to the other end of the line with the purpose of checking the connection, is adjusted at $-12 \mathrm{~dB}$, which can vary $\pm 1 \mathrm{~dB}$. The other telecommunication device transforms such a signal into a digital signal, which is transferred via digital network to the other end of the line. The analog frequency signal for transfer trip which is sent to other relays has the adjusted power of $-5 \mathrm{~dB}$. The allowed power of analog signal which can be transformed into digital signal is limited to $-4 \mathrm{~dB}$. Signals exceeding this level are distorted. According to the records from the telecommunication devices and relays it is obvious that there was a signal transmission delay. The 
analysis showed that the transfer trip signal (adjusted power of $-5 \mathrm{~dB}$ ) crossed the limit of $-4 \mathrm{~dB}$, and due to power limit became distorted. Amplification of signal is possible due to the growth of potential, resonant occurrences etc. Such a distorted signal was transformed by the second converter into a digital signal and sent to the other line end. The experience based conclusion was reached that such a digital signal that was transmitted did not have a satisfactory form. The transformation of such digital signal at the other end resulted in the delay of signal reception for the acceleration of relay operation.

It turned out that the above-mentioned adjustments of the telecommunication system were not satisfactory, so the values in the telecommunication devices were changed in the following way:

- Power of signal used for checking the connection between the converters was adjusted to $-6 \mathrm{~dB}$;

- power of signal sent as the order for the transfer trip remained $-5 \mathrm{~dB}$;

- strength limitation of signal transformed into a digital signal was adjusted to $0 \mathrm{~dB}$.

The unsuccessful fault clearance of actual fault while the line was in service confirmed our decision to perform a staged-fault testing.

\section{STAGED-FAULT ANALYSIS}

After readjustment of parameters on the telecommunication devices, the staged-fault tests on the $49^{\text {th }}$ tower from TPP Plomin to the tap point took place $(49.46$ $\%, 16.234 \mathrm{~km})$. Due to the arrangement of conductors on the $49^{\text {th }}$ tower the L2-E and L1-L2 tests took place (Fig.10).

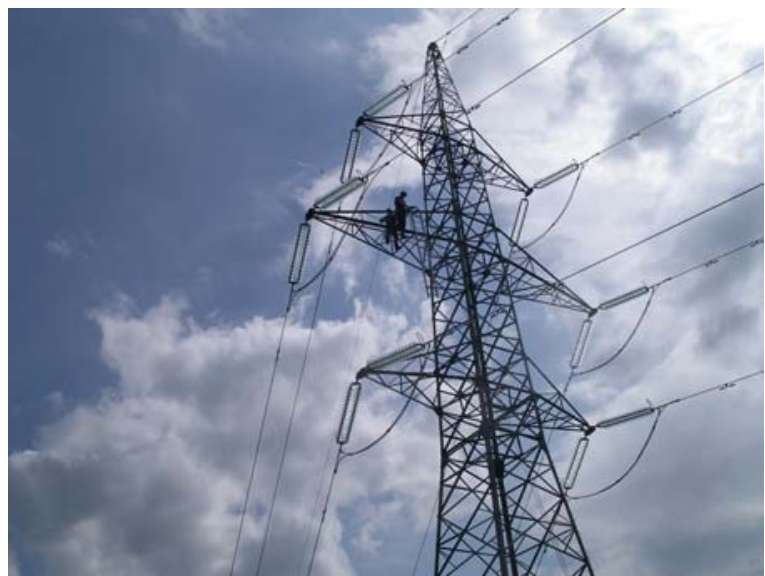

Fig.10. Conductor arrangement on the $49^{\text {th }}$ tower

Before testing, the line was outaged and a thin wire (1 $\mathrm{mm}^{2}$ ) was fastened to the phase L2, and moved aside from the tower with insulating string. After switching on the line, the insulating string was cut off; the wire fell on the tower which is earthed, which resulted in the fault L2-E. During the second testing (fault L1-L2) the same procedure as for the L2-E fault was applied. A thin wire was fastened to phase L1 and moved aside with insulating string. After switching on the line the string was cut off and the wire fell on the phase L2 which resulted in two-phase fault L1-L2 (Fig.13)

\section{A. Single-phase Fault Analysis}

Analog values and digital signals recorded by numerical relays during the L2-E fault are shown in Fig.11. Values in the analysis relevant to the comparison of relay operation were fault inception moment and fault current interruption:

- relay in TPP Plomin issues a command to trip the faulty phase, and the transfer trip signal $28 \mathrm{~ms}$ after fault inception, while fault current stops $63 \mathrm{~ms}$ after fault inception;

- location determined by the relay to the fault location is $51.1 \%$, i.e. $16.9 \mathrm{~km}$;

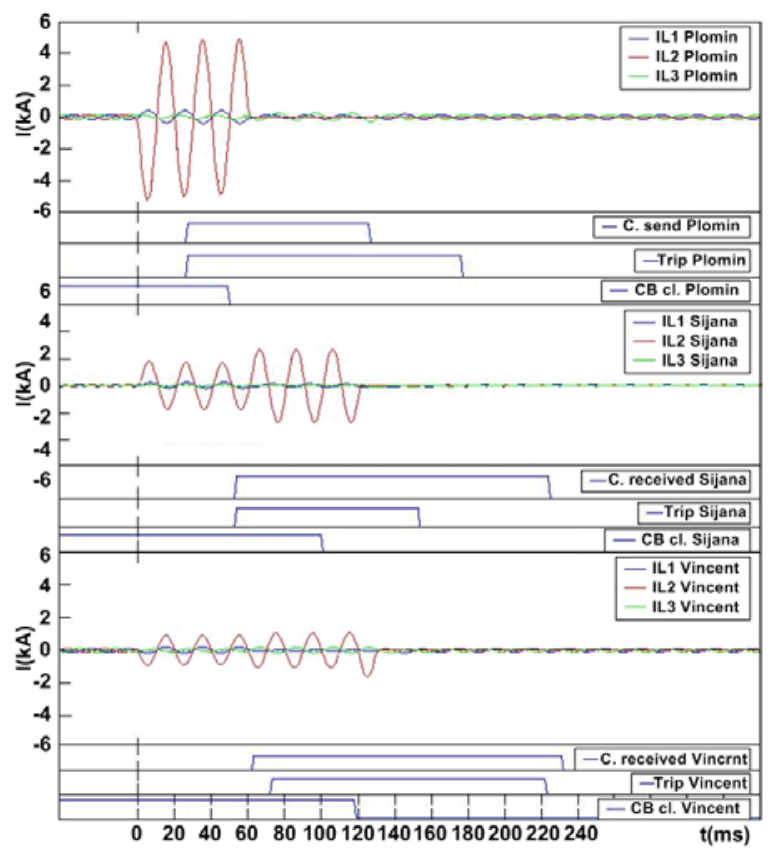

Fig.11. Analog and digital values during L2-E fault testing

- miscalculation in determining this location is $+2.04 \%$ of the line length, i.e. $0.67 \mathrm{~km}$;

- relay in SS Sijana detects fault in Z2, receives the transfer trip signal $54 \mathrm{~ms}$ after fault inception and issues an order to trip the faulty phase. Transfer of this acceleration order takes 26 ms. Fault current stops 122 ms after fault inception;

- relay in SS Vincent detects fault in Z2, receives the transfer trip signal $65 \mathrm{~ms}$ after fault inception and issues an order to trip the faulty phase. Transfer of this acceleration order takes $37 \mathrm{~ms}$. Fault current stops 133 ms after fault inception;

- $63 \mathrm{~ms}$ after fault inception fault current increases in SS Sijana and SS Vincent due to breaker switching in TPP Plomin which first tripped, so the fault is fed from SS Sijana and SS Vincent;

- $\quad 122 \mathrm{~ms}$ after fault inception fault current increases in SS Vincent as the consequence of breaker switching in SS Sijana, so the fault is fed only from SS Vincent;

the fault stops entirely $133 \mathrm{~ms}$ after fault inception following the relay operation in SS Vincent, which is 70 ms after fault current interruption in TPP Plomin, so all the relays successfully completed the cycle of the singlephase AR. 
The moment of signal for breaker closing operation through the relay AR operation is not shown because of a long dead time of $1.2 \mathrm{~s}$ which could not be shown in the same figure.

\section{B. Double-phase Fault Analysis}

Fig.12 shows analog values and digital signals recorded by numerical relays during the L1-L2 fault. Fig.13 shows the arc lightening during the L1-L2 testing on the tower. Values in the analysis relevant to the comparison of relay operation were fault inception moment and fault current interruption:

- relay in TPP Plomin issues a command for three-phase trip, and the transfer trip signal $28 \mathrm{~ms}$ after fault inception, while fault current stops $71 \mathrm{~ms}$ after fault inception;

- location determined by the relay to the fault location is $47.0 \%$, i.e. $15.5 \mathrm{~km}$;

- miscalculation in determining this location is $-2.46 \%$ of the line length, i.e. $-0.734 \mathrm{~km}$;

- relay in SS Sijana detects fault in Z2, receives the transfer trip signal $54 \mathrm{~ms}$ after fault inception and issues a command for three-phase tripping. Transfer of this acceleration order takes $26 \mathrm{~ms}$. Fault current stops 120 ms after fault inception;

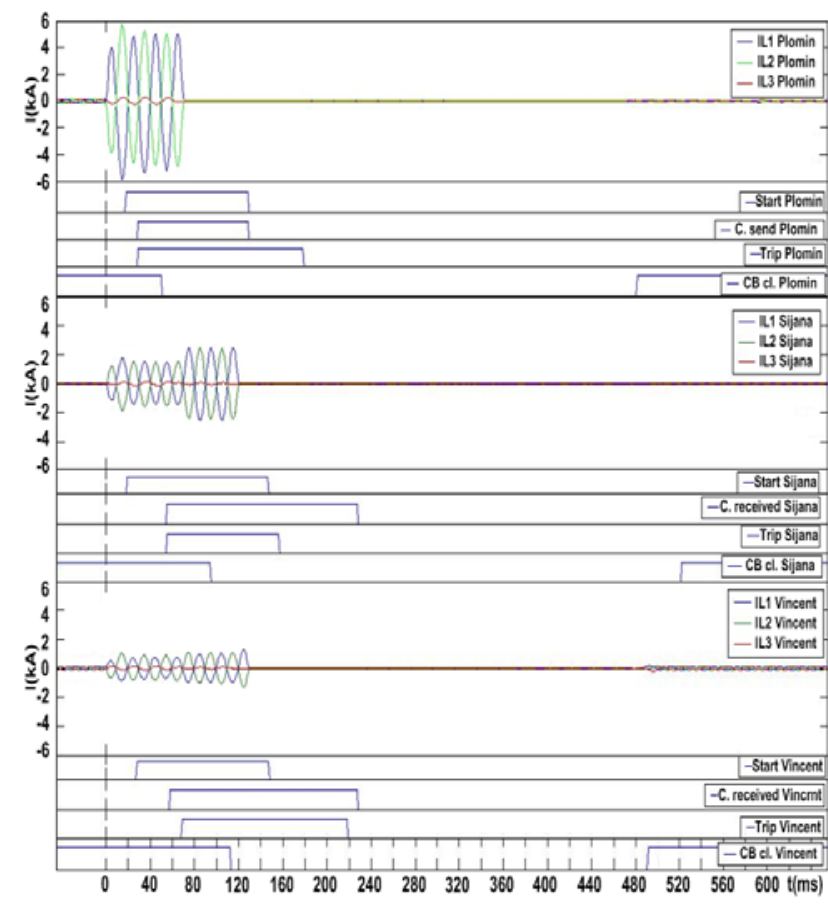

Fig.12. Analog and digital values during L1-L2 fault testing

- relay in SS Vincent detects fault in Z2, receives the transfer trip signal $59 \mathrm{~ms}$ after fault inception and issues a command for three-phase tripping. Transfer of this acceleration order takes $31 \mathrm{~ms}$. Fault current stops 130 ms after fault inception;

- the fault stops entirely $130 \mathrm{~ms}$ after fault inception following the relay operation in SS Vincent, which is 59 $\mathrm{ms}$ after fault current interruption in TPP Plomin
- relay in TPP Plomin issues a command for breaker closure $321 \mathrm{~ms}$ after fault inception. According to the record of the logical signal as to the position of the breaker, it was switched $382 \mathrm{~ms}$ after fault inception;

- relay in SS Sijana issues an order for breaker closure 392 ms after fault inception. According to the record of the logical signal as to the position of the breaker, it was switched $522 \mathrm{~ms}$ after fault inception;

- relay in SS Vincent issues a command for breaker closure $378 \mathrm{~ms}$ after fault inception. According to the record of the logical signal as to the position of the breaker, it was switched $490 \mathrm{~ms}$ after fault inception - all relays successfully completed the cycle of the threephase AR.

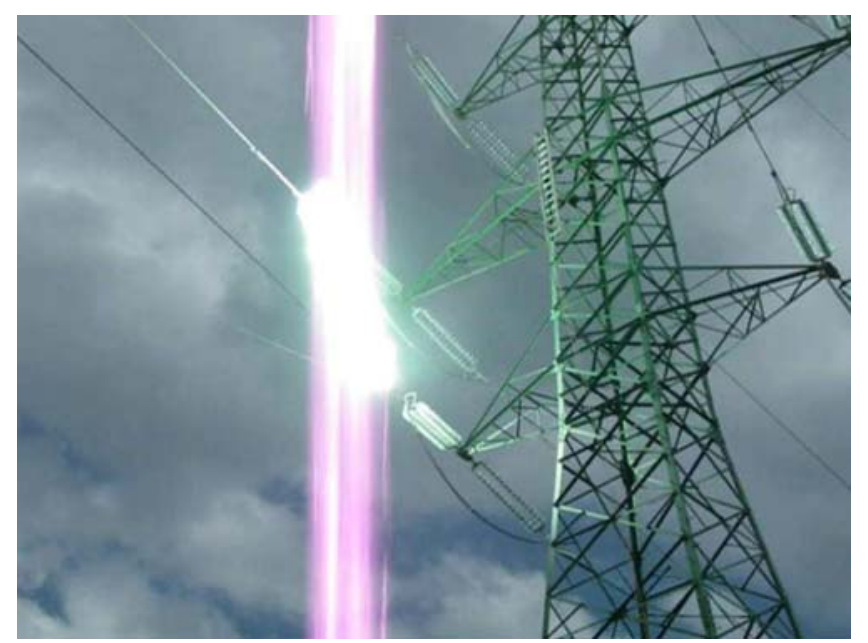

Fig.13. Arc flashing during L1 -L2 fault testing

\section{ANALYSIS OF RESULTS}

The values of the staged-fault testing were also used to verify the accuracy of the CAPE network model of the western part of the Croatian PS. The simulated faults in the network were used for the sequence definition for the endto-end testing, and the relays operated as predicted in the simulation. After the staged-fault testing the relay recordings were of great value to determine the accuracy of the model, since the network topology, location of the fault and the fault resistances were well known.

Analysis of analog values shows that the difference between the simulated values of the CAPE software and the values obtained from the numerical relay records are satisfactory. It is important to notice that since CAPE software for HEP TSO does not support the power flow, the pre-fault current is set to zero. Apart from that, the algorithm used for COMTRADE [17] export does not support the breaker operation, so the simulated fault current cannot be stopped.

\section{A. Result comparison for single line-to-ground fault}

The comparison of the single line-to-ground fault record form the relay and CAPE simulation are shown in numerical values in Table 4 and in graphical representation in Fig.14. The graphical record of the simulation was captured with a dedicated algorithm in CAPE for creating COMTRADE 
files of the fault. The values were then replayed in MATLAB software and compared with the relay recordings. It can be seen that the difference between the relay and simulation recordings is satisfactory, except for SS Vincent where the difference is the highest, $21 \%$.

Table 4. Result comparison for single linetoground fault (faulty phase)

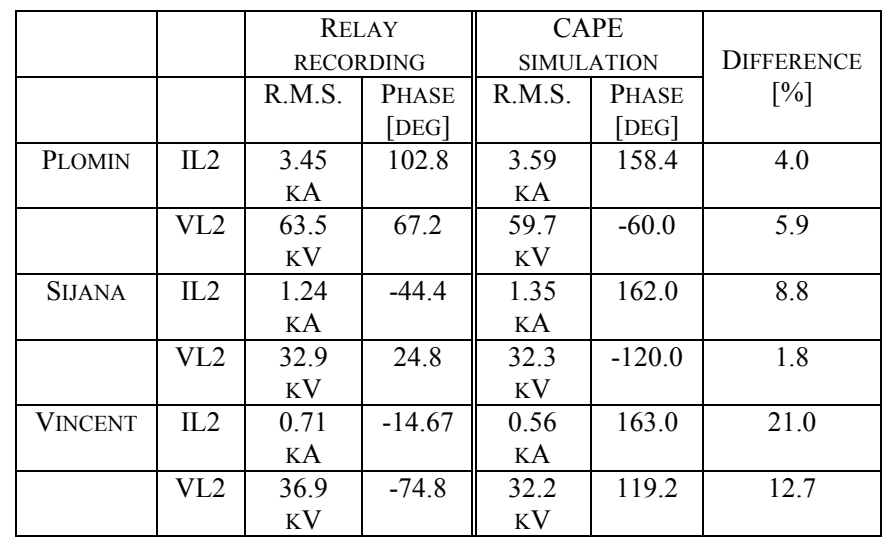

The interesting point in Fig.14 is the amplification of the relay current. This is due to the breaker operation in TPP Plomin, and the change of current flow in the network. Similar to the comparison for SS Sijana, for the relay in SS Vincent the current has one value at the fault inception, and this value increases when the relay at Plomin operates and issues a trip. The final increase is due to the relay operation in Sijana.

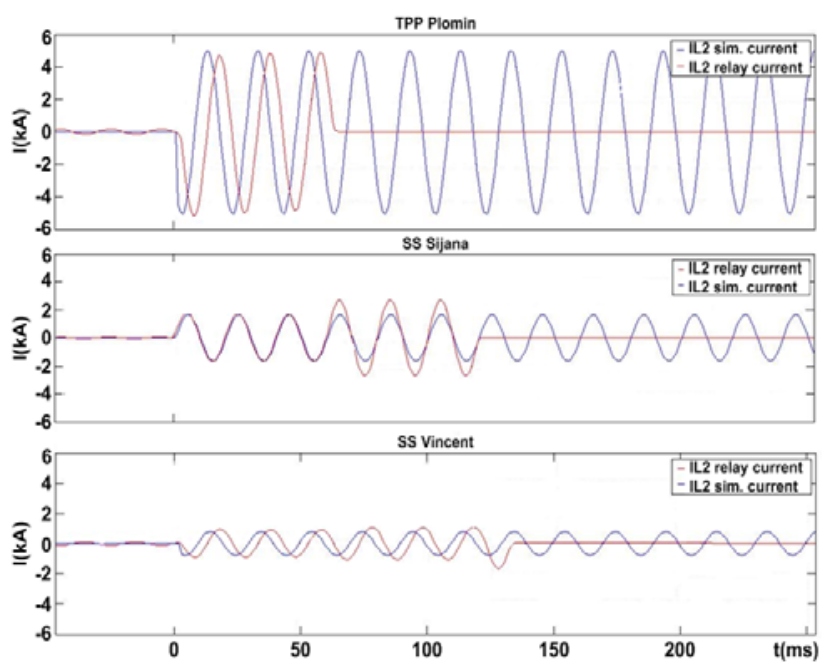

Fig.14. Comparison of relay and simulation currents for single linetoground fault

\section{B. Result comparison for phase-to-phase fault}

The comparison of the two phase-to-ground fault record from the relay and CAPE simulation are shown in numerical values in Table 5 and in graphical representation in Fig. 15. The graphical record of the simulation was captured in COMTRADE format. The values were then replayed in MATLAB and compared with the relay recordings. It can be seen that the difference between the relay and simulation recordings is satisfactory. The highest difference is for the relay at SS Sijana, and it amounts $19.2 \%$. The voltage difference is the highest for the relay at SS Vincent and it amounts $12 \%$.

Table 5. Result comparison for doublephase fault (faulty phases)

\begin{tabular}{|c|c|c|c|c|c|c|}
\hline & & \multicolumn{2}{|c|}{$\begin{array}{c}\text { RELAY } \\
\text { RECORDING }\end{array}$} & \multicolumn{2}{|c|}{$\begin{array}{c}\text { CAPE } \\
\text { SIMULATION }\end{array}$} & \multirow{2}{*}{$\begin{array}{c}\text { DIFFERENCE } \\
{[\%]}\end{array}$} \\
\hline & & R.M.S. & $\begin{array}{l}\text { PHASE } \\
{[\mathrm{DEG}]}\end{array}$ & R.M.S. & $\begin{array}{c}\text { PHASE } \\
{[\mathrm{DEG}]}\end{array}$ & \\
\hline \multirow[t]{4}{*}{ PLOMIN } & IL1 & $\begin{array}{l}3.88 \\
\text { KA }\end{array}$ & -30.4 & $\begin{array}{l}3.47 \\
\text { KA }\end{array}$ & -51.9 & 10.5 \\
\hline & IL2 & $\begin{array}{l}3.75 \\
\mathrm{KA}\end{array}$ & 150.4 & $\begin{array}{l}3.47 \\
\text { KA }\end{array}$ & 128.1 & 7.3 \\
\hline & VL1 & $\begin{array}{l}42.0 \\
\mathrm{KV}\end{array}$ & -10.7 & $\begin{array}{l}39.6 \\
\mathrm{KV}\end{array}$ & -22.8 & 5.6 \\
\hline & VL2 & $\begin{array}{l}41.6 \\
\mathrm{KV}\end{array}$ & -83.3 & $\begin{array}{l}40.0 \\
\mathrm{KV}\end{array}$ & -96.8 & 3.8 \\
\hline \multirow[t]{4}{*}{ SIJANA } & IL1 & $\begin{array}{l}1.04 \\
\mathrm{KA}\end{array}$ & 166.5 & $\begin{array}{l}1.24 \\
\mathrm{KA}\end{array}$ & -47.0 & 19.2 \\
\hline & IL2 & $\begin{array}{l}1.08 \\
\mathrm{KA}\end{array}$ & -15.7 & $\begin{array}{l}1.24 \\
\mathrm{KA}\end{array}$ & 132.0 & 14.8 \\
\hline & VL1 & $\begin{array}{l}37.2 \\
\mathrm{KV}\end{array}$ & 172.0 & $\begin{array}{l}36.7 \\
\mathrm{KV}\end{array}$ & -164.0 & 1.3 \\
\hline & VL2 & $\begin{array}{l}35.8 \\
\mathrm{KV}\end{array}$ & 119.4 & $\begin{array}{l}38.1 \\
\mathrm{KV}\end{array}$ & $\begin{array}{l}-89.1 \\
\end{array}$ & 6.4 \\
\hline \multirow[t]{4}{*}{ VINCENT } & IL1 & $\begin{array}{c}0.52 \\
\mathrm{KA}\end{array}$ & 158.3 & $\begin{array}{c}0.55 \\
\mathrm{KA}\end{array}$ & -47.0 & 7.1 \\
\hline & IL2 & $\begin{array}{c}0.61 \\
\mathrm{KA}\end{array}$ & -25.2 & $\begin{array}{c}0.55 \\
\text { KA }\end{array}$ & 133.0 & 5.3 \\
\hline & VL1 & $\begin{array}{c}37.5 \\
\mathrm{KV}\end{array}$ & 166.8 & $\begin{array}{c}33.0 \\
\mathrm{KV}\end{array}$ & -29.2 & 12.0 \\
\hline & VL2 & $\begin{array}{l}36.5 \\
\mathrm{KV}\end{array}$ & 109.7 & $\begin{array}{l}39.3 \\
\mathrm{KV}\end{array}$ & -89.6 & 7.8 \\
\hline
\end{tabular}

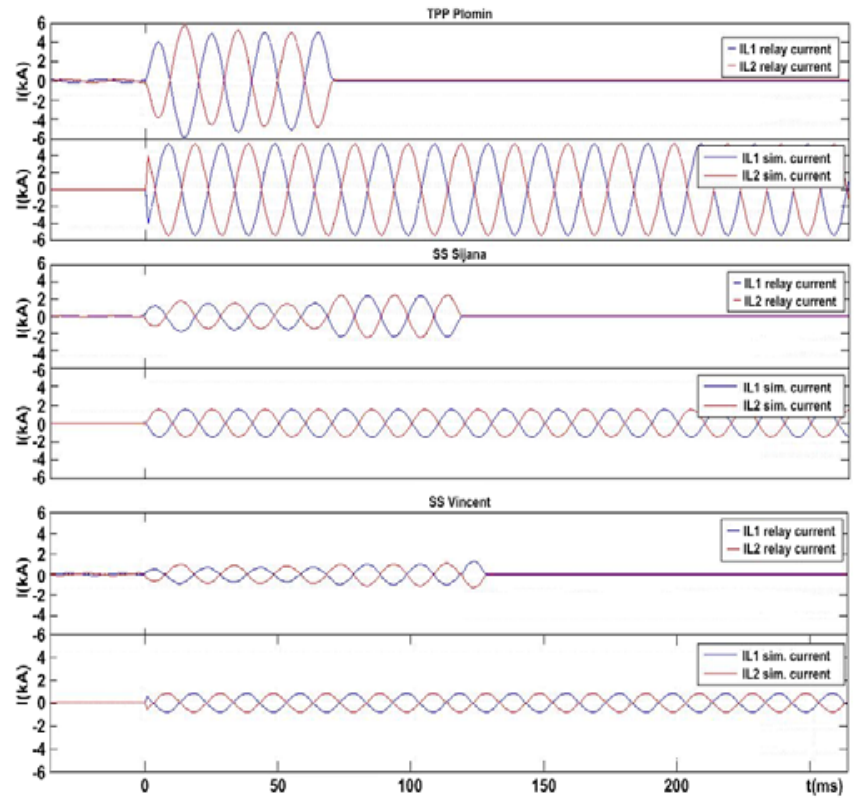

Fig.15. Comparison of relay and simulation currents for double-phase fault

After the analysis of the relay and simulation currents it was concluded that the simulated network complies with the staged-fault results, and it can be used in future simulations. Nevertheless, future improvements of the network and updating with additional data (mutual couplings, groundings...) are needed. 


\section{CONCLUSION}

The comparison of analog values (current and voltage) obtained by simulations using the CAPE software and values recorded by the relays during primary testing on the $49^{\text {th }}$ tower shows that the network in which the simulations took place is well-designed. Differences in values are within acceptable $4-10 \%$ for the TPP Plomin, 8-19 \% for the SS Sijana, and 5-20\% for the SS Vincent. The conclusion is that entry data for the secondary tests has been good.

Secondary tests conducted on the three-end line PlominSijana-Vincent, however, showed that such tests are sometimes not sufficient to get all the important data needed to ensure the security of the protected object. The test done by secondary injection of analog values (end-to-end) showed that the protection system worked correctly, but during an actual fault it became obvious that it was not entirely satisfactory, i.e. that conditions during secondary tests and during actual faults were not the same.

After intervention in the communication system and change of certain parameters, primary tests were performed which supposed to show how the protection system worked in real life conditions of fault. The tests showed that the protection system on the three-end line TPP Plomin-SS Sijana-SS Vincent worked correctly. All the parameters relevant for the correct operation of the power system were satisfactory. Analysis of the records by numerical relays shows that, despite using two converters and digital network as a medium, the transmission of transfer trip signal takes less than $40 \mathrm{~ms}$.

Non-synchronized trips and ARs of the circuit breaker did not lead to instability in the power system. Thus, the conclusion can be reached that such a relay protection configuration meets the conditions of the mentioned power plant in the power system.

Several faults on the line in question followed after the staged faults, during which the protection system worked correctly. This type of relay protection system in many ways depends on the availability of a reliable telecommunication system. Thus, the protection scheme cannot be observed separately, but as a unique complex system together with telecommunication resources.

\section{REFERENCES}

[1] Jiali, H., Zheng, G. (2002). The research of relay protection of three-terminal power transmission lines using optical fiber channel. In PowerCon 2002 : International Conference on Power System Technology, 13-17 October 2002. IEEE, Vol. 2, 696701.

[2] Carpenter, M., Hoad, R.R., Bruton, T.D., Das, R., Kunsman, S.A., Peterson, J.M. (2005). Staged-fault testing for high impedance fault data collection. In Protective Relay Engineers : 58th Annual Conference, 5-7 April 2005. IEEE, 9-17.

[3] Xia, Y.Q., David, A.K., Li, K.K. (1994). Highresistance faults on a multi-terminal line: Analysis, simulated studies and an adaptive distance relaying scheme. IEEE Transactions on Power Delivery, 9 (1), 492-500.
[4] Amoda, O.A., Schulz, N.N. (2007). An adaptive protection scheme for shipboard power systems. In ESTS '07 : IEEE Electric Ship Technologies Symposium, 21-23 May, 2007. IEEE, 225-230.

[5] Hu, Z., Fan, J., Chen, M., Xu, Z. (2009). New method of live line measuring the parameters of t-connection transmission lines with mutual inductance. In PES '09 : IEEE Power \& Energy Society General Meeting, 2630 July 2009. IEEE.

[6] Alexander, G.E., Andrichak, J.G. (1998). Application of phase and ground distance relays to three terminal lines. Document GER-3964. Ontario, Canada: GE Power Management.

[7] Cheung, H., Hamlyn, A., Wang, L., Yang, C., Cheung, R. (2009). New simple formulations and validations for digital implementation of pilot protective relaying schemes. In PES '09 : IEEE Power \& Energy Society General Meeting, 26-30 July 2009. IEEE.

[8] CIGRÉ Joint Working Group 34/35.11. (2000). Protection Using Telecommunications. Final Report. International Council on Large Electric Systems.

[9] Electrocon International, Inc. (2000). CAPE Short Circuit Tutorial.

[10] Electrocon International, Inc. (2000). CAPE Coordination Graphics Tutorial.

[11] Frlan, K. (2006). Analysis of Influence of Intermediate In-feeds and Fault Resistance Upon Distance Protection Functionality. Master Thesis, Faculty of Electrical Engineering and Computing, University of Zagreb.

[12] Frlan, K., Rubeša, R., Marušić, A. (2007). Influence of new over-head power lines on the operation of the relay protection system. In AFRICON $2007: 8^{\text {th }}$ IEEE Conference, 26-28 September 2007. IEEE.

[13] Agudo, M.E., Kasperek, B., Thompson, S.I. (2001). End-to-end relay testing using GPS-synchronized secondary injection. In Developments in Power System Protection : 7th International Conference, 9-12 April, 2001. IEEE, 42-45.

[14] Odon, A. (2007). Circuit breakers timing test system. Measurement Science Review, 7 (5), 55-58.

[15] Ptak, P., Kurkowski, M., Biernacki, Z., Zloto, T. (2001). Digital measuring system for recording deformed functions. Measurement Science Review, 1 (1), 51-54.

[16] Espel, P., Poletaeff, A., Ndilimabaka, H. (2010). Traceability of voltage measurements for nonsinusoidal waveforms. Measurement Science Review, 10 (6), 200-204.

[17] C37.111-1999 - IEEE Standard Common Format for Transient Data Exchange (COMTRADE) for Power Systems. (1999). IEEE Standards Association.

Received December 1, 2011. Accepted May 25, 2012. 